Nepalese Vet. J. 35:77- 83

\title{
Semen Extender Ratio and Season's Effects on Hatchability of Turkeys in Nepal
}

\author{
A. Subedi ${ }^{1 *}$, S. Gurung ${ }^{1}$, M. Sharma ${ }^{1}$, S. Bhandari ${ }^{2}$, N. Bhattarai ${ }^{1}$ \\ ${ }^{1}$ Agriculture and Forestry University, Rampur, Chitwan \\ ${ }^{2}$ Nepal Agriculture Research Council, Khumaltar, Lalitpur \\ *Corresponding author: sanubedi369@gmail.com
}

\begin{abstract}
This study was carried out to identify the effects of season and semen extender ratio on hatchability of artificially inseminated turkeys of Chitwan, Nepal. Trials were conducted using four treatments of different dilutions of semen with skim milk powder in the ratio of 1:1 (T1), 1:2 (T2), 2:3 (T3) and 3:4 (T4). The 32 turkeys were artificially inseminated in 4 days interval for 3 months. The dose of insemination was $0.03 \mathrm{ml}$ and insemination were done around 6:00 p.m. Trials were done in winter and spring seasons of 2017 to find out the seasonal variation on hatchability of turkey. The data were analyzed using GenStat3.6.2, computer software. The hatchability was noted on total eggs as well as fertile eggs. In total eggs, it was found that hens with T1 (67.80\%) gave higher hatchability than T2 (63.82\%), T3 (63.04\%) and T4 (63.98\%) whereas in fertile eggs, T3 (83.26\%) and T4 (83.01\%) gave higher hatchability than $T 1$ (82.96\%) and T2 (82.90\%). Hatchability rate was almost similar in both spring and winter seasons in total eggs with non-significant differences. On the other hand, in fertile eggs, the hatchability rate was found higher in spring season. Similarly, seasonal effect on hatchability rate of various semen extender ratios in total eggs and fertile eggs was also carried out. In total eggs, T1 and T3 produced higher hatchability rate in spring than in winter; T2 had similar hatchability rate in both seasons and T4 had higher hatchability in winter than in spring. However, there were no significant differences on hatchability rate of semen extender ratio due to seasonal variation. In fertile eggs, all the 4 dilutions had more hatchability rate in winter season than in spring with significance $(P<0.05)$. The hatchability was highest in $T 1$ (85.19\%) in winter season. The present study provides evidence that in total eggs of turkey inseminated with 1:1 semen dilutions provides more hatchability rate than other dilutions, whereas fertile eggs have more hatchability with dilutions 1:2 and 2:3 than others and hatchability rate based on total eggs is higher in spring than winter.
\end{abstract}

Keywords: Artificial Insemination, Semen Extender Ration, Hatchability, Fertility 


\section{INTRODUCTION}

Turkey farming is flourishing in Nepal day by day due to its healthy meat. There are about 1 lakh Turkeys in Nepal contributing 2 quintal of meat per day. Turkey could be one of the potential commodities in enhancing the livelihood and nutritional security in the rural households of developing countries. However, promotion and commercialization of this species is scarcely done at government and non-government level. It has been experienced by the commercial growers that female turkeys get injured due to tearing of skin down to muscles by heavy males during mating. In this regard, artificial insemination is followed in turkey farming which has been found to be successful.

Artificial insemination in turkey began in 1930 when Beltsville based researchers William Burrow and Joseph Quinn in 1937 reported groundbreaking methods for semen collection and Artificial Insemination (AI) for poultry. The artificial insemination in turkey has continued to flourish and this has aided turkey farms since large number of poultry can be gotten through artificial insemination. Its use in turkey breeding is widespread due to the development of heavy, broad breasted bird with a conformation which makes natural mating difficult. As a result, it has become the only method for economic poultry production and some $95 \%$ of this success results from an artificial insemination breeding program (Marire, 2011). Low fertility in turkeys, due to unsuccessful mating caused by large body size of the tom and reduced libido is a serious and costly problem in the production of hatching turkey eggs (Merck pub., 2008). Artificial insemination is a common practice in the poultry industry with the turkey industry in North America and Europe using it almost exclusively to produce hatching eggs. It is also important as with AI, a greater number of females (about 18) can be fertilized than with natural mating where 1 tom can be used to fertilize 5 females only. The use of AI in turkey is enhanced with the improvement of diluents and breeding in appropriate season. As very small amount of semen is ejaculated at a time i.e. 0.2 to $0.5 \mathrm{ml}$ so, appropriate diluents make it possible to increase its volume thereby enabling the spread of semen over many more turkeys. Important too is the decrease in ratio of toms from 1 to 10 with natural mating to 1 to 30 with Artificial Insemination (Tara, 1998). In past, some researchers have successfully employed various diluents for turkey semen like ringers' lactate, sodium phosphate buffer, egg yolk, egg white, milk and tyrode solutions. Diluent or extender refers to the aqueous solution used to increase the volume of the ejaculate to a level appropriate for making multiple inseminations (Salisbury et al., 1978; Foote, 1980). Undiluted semen dies or loses its fertilizing capacity in about 4-6 hours at room temperature. Its life may be slightly prolonged by slow cooling to 100C (Gadea, 2003). Dilution reduces the 
number of spermatozoa per ml of semen. Munro (1938) found a decline in sperm numbers with increasing dilution, but the decline is only appreciated when the dose of insemination contained less than the minimum number of spermatozoa required for optimum fertility (Brown et al., 1970; LLinskii et al., 1975). Loss of fertility following excessive dilution of semen could result by inseminating chickens weekly with semen diluted 1:4. Sexton (1986) reported that fertility of stored turkey semen diluted 1:2 was lower than that of semen diluted 1:1 and 2:1.

There have been very limited studies carried out in Nepal focusing to assess hatchability and fertility of Turkey to date. Very small amount of semen is ejaculated at a time i.e. 0.2 to $0.5 \mathrm{ml}$. Thus, appropriate diluents could make it possible to increase its volume thereby enabling the use of semen over many more turkeys. The influence of weather (i.e. season of production) on hatchability has not been adequately studied in the chicken. This may also influence egg quality before incubation especially during summer when environmental temperatures are high (Tona et al., 2007). Considering the above-mentioned facts, present experiment was carried out specially aiming to know the most appropriate season of $\mathrm{AI}$ and the semen-extender ratio to increase hatchability of turkeys in Chitwan, Nepal.

\section{MATERIALS AND METHODS}

This study was conducted on a commercial turkey farm at Chitwan, Nepal in 2017. Ten months old laying turkeys were taken for study purpose. The experiment was done in imbalanced design due to the differences in the availability of turkeys for insemination according to the differences in the season. Altogether 32 turkeys were separated in different cages without any Tom for 3 months. Tom was isolated from hens a day before insemination. All those turkeys were given proper similar care, feed as well as sufficient time for grazing in the field. The diluent was prepared by adding two spoonsful of water in one spoonful of skim milk powder. Collection of semen from Tom was done with the help of tuberculin syringe after massaging and stimulating its sex organ and kept in a glass beaker. Then semen and diluent were mixed at different ratios. The mixture was then inseminated to all turkeys equally i.e. $0.03 \mathrm{ml}$ using tuberculin syringe.

Different trails were conducted using various dilutions i.e. dilution ratio of 1:1 (T1), 1:2 (T2), 2:3 (T3) and 3:4 (T4). Insemination was performed in every 4 days. From the day after insemination, eggs were collected from inseminated turkeys thrice a day. Each egg was marked and kept in hatchery for hatching. Every day, for 3 months i.e. from winter to spring, the number of marked fertile eggs from hatchery was recorded. As different dilutions were done on different days, the hatchability rate of different 
dilution rate was recorded accordingly. The data collected during the experimental period were analyzed using GenStat3.6.2, computer software. The statistical model used in analyzing the data of this experiment is presented here under:

$Y_{i j k}=\mu+a_{i}+b_{j}+(a b)_{i j}+e_{i j k}$

Where,

$Y_{i j k}$ is the adjusted mean of the hatchability

$\mu$ is the overall mean

$a_{i}$ is the effect of $i^{\text {th }}$ season

$b^{j}$ is the effect of $j^{\text {th }}$ semen extender ratio

$(a b)_{i j}$ is the effect of $j^{\text {th }}$ semen extender ratio in $i^{t h}$ season distributed

$e_{i j k}$ is the residual (error) term that is assumed to be normally and independently

\section{RESULT AND DISCUSSION}

\section{Hatchability Based on Total Eggs}

Results of present study revealed that the overall mean hatchability based on total eggs was 64.1. Season; semen extender ratio and the interaction between season and semen extender ratio had no significant influence on hatchability of artificially inseminated turkeys based on total eggs as per this study. However, higher rate of hatchability was observed for spring season as compared to winter season. Similarly, greater value of hatchability was observed in case of the turkeys inseminated with the diluted semen at the rate of 1:1 (T1). The result indicated that there is high hatchability rate of artificially inseminated turkey in spring than in winter. However, there are no such significant differences. It was found that $\mathrm{T} 1$ has high hatchability rate than others though there was no significant differences observed. Likewise, T1 and T3 have higher hatchability rate in spring than in winter; $\mathrm{T} 2$ has similar hatchability rate in both seasons whereas T4 has higher hatchability in winter than in spring. However, there were no significant differences on hatchability rate of semen extender ratio due to seasonal variation (Table 1). 
Table 1: Effect of season and semen extender ratio on Hatchability (\%)

\begin{tabular}{|c|c|c|}
\hline Factors & $\begin{array}{c}\text { Hatchability based } \\
\text { on total eggs }\end{array}$ & $\begin{array}{c}\text { Hatchability based on } \\
\text { fertile eggs }\end{array}$ \\
\hline Overall mean & 64.1 & 83.1 \\
\hline \multicolumn{3}{|l|}{ Seasons } \\
\hline Winter & 64.07 & 83.68 \\
\hline Spring & 64.59 & 82.31 \\
\hline Significance & NS & $* *$ \\
\hline \multicolumn{3}{|c|}{ Semen extender ratio } \\
\hline $1: 1$ & 67.80 & 82.96 \\
\hline $1: 2$ & 63.82 & 83.26 \\
\hline $2: 3$ & 63.42 & 83.01 \\
\hline $3: 4$ & 63.98 & 82.90 \\
\hline Significance & NS & NS \\
\hline \multicolumn{3}{|c|}{ Semen extender ratio $X$ Season } \\
\hline 1:1 X Winter & 67.65 & 85.19 \\
\hline 1:1 X Spring & 68.00 & 80.00 \\
\hline 1:2 X Winter & 63.97 & 83.34 \\
\hline 1:2 X Spring & 63.61 & 83.14 \\
\hline 2:3 X Winter & 62.17 & 83.76 \\
\hline 2:3 X Spring & 65.08 & 82.00 \\
\hline 3:4 X Winter & 64.60 & 83.00 \\
\hline 3:4 X Spring & 63.16 & 82.76 \\
\hline Significance & NS & $*$ \\
\hline
\end{tabular}

Note: *Significant at $95 \%$ confidence limit $(\mathrm{p}<0.05), * *$ Significant at $99 \%$ confidence limit $(\mathrm{p}<0.01)$, NS: Non-significant 


\section{Hatchability Based on Fertile Eggs}

The overall mean hatchability based on fertile eggs was $83.1 \%$. Hatchability based on fertile eggs was significantly affected by the season of insemination $(\mathrm{P}<0.01)$ and semen-extender ratio $(\mathrm{P}<0.05)$. But the semen extender ratio had no significant influence on hatchability. The result indicated that there is high hatchability rate of artificially inseminated turkey in winter than in spring season with significance of $\mathrm{P}<0.01$. It was found that $\mathrm{T} 2$ has high hatchability rate than others, however there was no significant differences observed. All the 4 dilutions had more hatchability rate in winter season than spring with significance of $\mathrm{P}<0.05$. The hatchability was highest with $\mathrm{T} 1$ in winter season (Table 1).

Similar to our result, hatchability rate of fertile eggs in winter season was higher than spring season (Tona et al., 2007). In case of month wise hatchability whereas winter $(57.676 \%)$ shows the highest followed by summer $(54.135 \%)$ and monsoon or rainy season (49.134\%) (Chowdhury, 2004).

\section{CONCLUSION}

Based on the findings of present study, it can be concluded that total eggs of turkey inseminated with 1:1 semen dilution provides more hatchability rate than other dilutions, whereas fertile eggs have more hatchability rate with dilutions 1:2 and 2:3 than other dilutions. Similarly, Hatchability rate was almost similar in both spring and winter seasons in total eggs with non-significant differences. On the other hand, in fertile eggs, the hatchability rate was found higher in spring season. Knowing the above findings, turkey farmers can pre-plan the best season, semen-extender ratio for insemination and use the knowledge of interaction of season and semen-extender ratio.

\section{ACKNOWLEDGEMENTS}

The authors would like to express our sincere acknowledgements to the faculty members of Department of Animal Breeding and Biotechnology; Faculty of Animal Science, Veterinary Science and Fisheries; Agriculture and Forestry University for their constant guidance and technical supervision during the entire study period. Besides, we would also like to thank Mr. Laxman Ghimire, proprietor of Haraiya Turkey Farm at Chitwan of Nepal for providing the facilities to carry out this experiment in his farm. 


\section{REFERENCES}

Brown, K. I.; Nestor, K. E and Topscher, M. (1970). A comparison of various methods of estimating spermatozoa concentration of turkey semen. Poultry Sci., 49: 295-299.

Burrows, W. H. and Quinn, J. P. (1937). The collection of spermatozoa from the domestic fowl and turkey. Poult. Sci., 16: 19-24.

Chowdhary, M.M.I. (2004). Effect of season on hatchability of duck eggs. DOI:10.3923/ijps.419.421.

Foote, R. H. (1980). In “Reproduction in farm Animals (E.S.E., Hafez, ed.)

Gadea, J. (2003). Semen extender used in the artificial insemination of Swine. Spanish Journal of Agricultural Research, 1(2): 17-27.

LLinskii, E. V.; Ten, E. B.; Tolstov, V. A. and Strelkova, L. I. (1975). Artificial Insemination of caged hens. A.B.A. 43(5) no. 2048.

Marire B. N (2011). Farm Animals, Features, Husbandry, Health and Production.

Merck...Pub., (2008). Artificial insemination: Introduction. Disclaimer/Feedback. www.merckmanuals.con/vet/poultry/ar...

Mounro, S. S. (1938). The effect of dilution and density on the fertilizing capacity of fowl sperm suspensions. Canad. J. Res. D., 16:281-299.

Salisbury, G. W.; Vandermark, N. L. and Lodge, J. R. (1978). Physiology of reproduction and artificial insemination in cattle, $2 \mathrm{nd} \mathrm{ed}$. W. H. Freeman and Co., p. 247-417.

Sexton, T. I. (1986). Comparison of Commercial diluents for holding turkey semen 24 hours at 40C. Poult Sci., 67:131-134.

Tara W. (1998). Spotting top-notch toms-males turkeys. How Researchers are re Volutionizing turkey production-Agric. Res.

Tona, K., Onagbesan, O., Ketelaere B.De., Bruggeman, V. and Decuypere, E. (2007). A model for predicting hatchability as a function of flock age, reference hatchability, storage time and season. European Poultry Science. 71(1): S,3034. 